\title{
A FEIRA É LIVRE (?): ESTUDO SOBRE FENÔMENOS SOCIAIS, SÍMBOLOS E SIGNIFICADOS DO COTIDIANO DE UMA FEIRA DA BAHIA
}

\section{THE FAIR IS FREE (?): STUDY ON SOCIAL PHENOMENA, SYMBOLS AND MEANINGS OF THE DAILY LIFE OF A FAIR IN BAHIA}

\author{
Sheilla Kalle Lima Martins \\ Graduada em Nutrição - Universidade Federal do Oeste da Bahia \\ sheillakalle@gmail.com \\ Marlus Henrique Queiroz Pereira \\ Doutorando em Saúde Coletiva - Universidade Federal do Espírito Santo \\ Docente do Centro das Ciências Biológicas e da Saúde - Universidade Federal do Oeste da Bahia \\ marlus.pereira@ufob.edu.br \\ Debora Cruz Porcino \\ Mestra em Alimentos, Nutrição e Saúde - Universidade Federal da Bahia \\ Docente do Centro das Ciências Biológicas e da Saúde - Universidade Federal do Oeste da Bahia \\ debora.porcino@ufob.edu.br
}

\begin{abstract}
RESUMO
O presente estudo tem como objetivo analisar os significados acerca da "comida de feira" sob a ótica de mulheres trabalhadoras em uma feira livre, bem como suas acepções sobre alimentação saudável. Situado no campo das ciências da saúde e socioantropologia, a pesquisa foi desenvolvida a partir de uma abordagem qualitativa, construída a partir de observação direta com registro em diário de campo e entrevistas semiestruturadas contendo questões norteadoras. Os resultados foram organizados em quatro categorias, sendo estas: "Primeiro olhar sobre a feira", que apresenta uma visão geral do espaço em estudo; Faces da reforma: "feira hoje parece que tem um dono", que discorre sobre os impactos da recente reforma da feira livre; "O se tornar feirante", que dialoga sobre a construção da profissão de feirante; Comida de feira: "aqui tem comida de todo tipo", onde é feita uma análise da comida da feira livre e a acepção do saudável. Com este estudo, conclui-se que a feira livre, sob a perspectiva das feirantes, configura-se como cenário para além da distribuição e comercialização de alimentos. As percepções sobre a comida de feira e as nuances do conceito de saudável também ultrapassam os aspectos nutricionais e incluem valores socialmente construídos.
\end{abstract}

Palavra-chave: Feira Livre. Alimentação Saudável. Cultura. Mulheres Trabalhadoras. Segurança Alimentar e Nutricional.

\begin{abstract}
The present study aims to analyze and discuss the social and eating behaviors of market participants, as well as to evaluate the meanings about "fair food" and their meanings of healthy eating. Situated in the field of socio-anthropology and health, the research was developed from a qualitative approach, built from direct observation with record in a field diary and semi-structured interviews containing guiding questions. The results were organized into four categories, these being: "First look at the fair", which presents an overview of the space under study; Faces of the reform: "the fair today seems to have an owner", who discusses the impacts of the recent reform of the open market; "Becoming a market trader", which discusses the construction of the market trader profession; Fair food: "there are all kinds of food here", where an analysis of the food in the open market and the meaning of healthy is made. With this study it is concluded that the free Market, from the perspective is of the marketers is configured as a scenario beyond the distribution and commercialization of food. Perceptions about market food and the nuances of the healthy concept also go beyond nutritional aspects and include socially constructed values.
\end{abstract}

Keywords: Street Market. Healthy Eating. Culture. Working Women. Food and Nutrition Security.

Recebido em: 10/09/2020

Aceito para publicação em: 03/04/2021. 


\section{INTRODUÇÃO}

As feiras livres são espaços que reúnem diversos elementos culturais, que representam a territorialidade de um povo. Com origem na virada do século XIX, são caracterizadas como modalidade varejista ao ar livre, voltada para a comercialização de gêneros alimentícios e produtos básicos diversos (MASCARENHAS; DOLZANI, 2008, p. 74).

Inicialmente localizadas distantes dos centros das cidades e lugares privilegiados, situam-se próximos a bairros periféricos das camadas populares da sociedade (MINNAERT, 2008, p. 130). Atualmente, as feiras presentes nas cidades do interior do Brasil representam em alguns casos a única forma de comércio local, e possuem a função de preservar a cultura nativa, além de servir como entretenimento (FERNANDES et al., 2014, p. 3).

A significância econômica e comercial da feira abrange não somente a vida dos feirantes, que tem naquele ambiente uma forma de sustento, mas representa o universo dos consumidores que veem no local uma forma economicamente mais favorável para adquirir os alimentos do consumo familiar. A feira reflete também um local de sociabilidade, aproximando as pessoas e fortalecendo os laços entre quem comercializa e consome os alimentos (ALMEIDA; PENA, 2011, p. 112).

Para além de um espaço caracterizado por esses processos de comercialização e distribuição de alimentos, a feira é também um lugar repleto de símbolos sociais que resistem e se apropriam de um espaço urbano concebendo uma "experiência peculiar de sociabilidade e de uso da rua" (MASCARENHAS; DOLZANI, 2008, p. 74).

Fazendo uma alusão ao livro de Roberto DaMatta (1997, p. 40) - "A casa \& a Rua", a feira torna-se um local de ambiguidade, sendo uma conexão entre esses dois espaços. Por um lado, retratando a hospitalidade, a calma e o repouso pertencentes ao ambiente doméstico, e por outro, o lugar de movimento que pertence ao "povo" ou ao "governo", tal qual se percebe nas ruas.

Estes dois ambientes possuem peculiaridades que podem ser retratadas no cotidiano da feira. $O$ universo doméstico, historicamente é conhecido pela atuação da mulher nos processos que envolvem a transformação do alimento em comida, enquanto os homens se mantêm responsáveis por trazer o alimento para o sustento da casa.

No mundo contemporâneo, a divisão social de tarefas entre gênero masculino e feminino ainda é presente. Desta forma, homens e mulheres ocupam cozinhas diferentes, onde mulheres cozinham no espaço familiar e homens cozinham para estranhos, em restaurantes na "rua". Sendo assim as feiras livres permitiram a criação de um contexto onde o gênero feminino adquiriu um importante papel dentro do núcleo familiar, com objetivo de obtenção de renda (ANACLETO; COELHO; CURVELO, 2016, p. 119).

A literatura relacionada a este tema aponta que as feiras livres de modo geral são lócus de diversos estudos, que abordam aspectos técnicos e sociais sobre parâmetros higiênicos-sanitários, assim como os alimentos comercializados, preparados e consumidos neste local. Considerando a riqueza cultural do ambiente das feiras, este estudo se propõe adentrar o campo das investigações que contemplem os fenômenos sociais, símbolos e significados presentes neste local, assim como seus agentes sociais que compõe toda sua dinâmica.

Sendo assim, objetiva-se analisar os significados acerca da "comida de feira" sob a ótica de mulheres trabalhadoras em uma feira livre de Barreiras-BA, assim como suas acepções sobre alimentação saudável.

\section{METODOLOGIA}

O presente estudo integra um projeto maior intitulado "Hábitos Alimentares no município de BarreirasBA: investigação sobre permanências, modificações e ressignificações a partir de fluxos migratórios", desenvolvido pelos pesquisadores do Núcleo de Estudos e Pesquisas sobre Hábitos Alimentares e Saúde - NEPHANS. O projeto passou pela aprovação do Comitê de Ética e Pesquisa da Universidade Federal do Oeste da Bahia (UFOB), com o parecer de número 3.103.913.

Conforme a Resolução № 466, de 12 de dezembro de 2012, que regulamenta pesquisas que envolvam seres humanos, os participantes receberam o Termo de Consentimento Livre e Esclarecido (TCLE) registrando a participação como voluntario na presente pesquisa e foram informados da natureza e objetivo do estudo. As identidades foram preservadas e os nomes trocados por siglas.

DOI: http://dx.doi.org/ 10.14393/Hygeia17057222 $\quad$ Hygeia $\quad$ v.17 $\quad$ p.110-120, 2021 página 111


Situado nas áreas das ciências da saúde e socioantropologia, esta pesquisa é construída a partir de uma abordagem qualitativa, visando compreender os fenômenos sociais da alimentação. A metodologia de pesquisa qualitativa foi escolhida pois dispõe de técnicas que permitem responder a questões particulares, trabalhando com o universo de crenças, valores e significados dos fenômenos sociais que não podem ser operacionalizados em variáveis (MINAYO et al., 2002, p. 21-22).

Sendo assim, este estudo foi desenvolvido no Centro de Abastecimento de Barreiras - CAB, conhecido como feira livre da cidade, que se localiza no centro e é considerada um importante polo de comercialização de alimentos para a região Oeste da Bahia.

Como sujeitos da pesquisa, foram escolhidas mulheres trabalhadoras de uma feira livre. Tal recorte se faz pelo gênero feminino ser predominante no campo de estudo, bem como por considerar que esta característica social está em sua maioria associada à comensalidade em todas as suas dimensões. Assim, torna-se relevante investigar todo o processo em torno do comer, a partir dessa ótica. As feirantes foram denominadas "informantes-chave", e como critérios de inclusão foram escolhidas: mulheres maiores de idade e que trabalhassem diariamente na feira livre.

Os "informantes-chave" se caracterizam por serem pessoas capazes de fornecer informações acerca da realidade a ser estudada e por deterem conhecimentos particulares que permitem neutralizar possíveis vieses ocasionados pela presença do pesquisador no local (JACCOUD; MAYER, 2008, p. 271).

Como elementos que compõem a construção dos dados, foram utilizados dois instrumentos, a saber: observação direta e entrevistas semiestruturadas. Como primeiro procedimento, a observação direta é usada na pesquisa qualitativa pois as anotações são utilizadas para descrever e compreender a situação, indo além de números para enumerar a frequência em que o comportamento ocorre, esta técnica permite um contato direto com os informantes não havendo interferência do pesquisador na situação observada (JACCOUD; MAYER, 2008, p. 254).

Para registro do que foi observado nas idas na feira, foi feito uso de diários de campo, com intenção de descrever e analisar a dinâmica espacial/social da feira e dos feirantes, identificar os tipos de espaço de comensalidade, perceber os sujeitos que se alimentam naquele espaço e auxiliar na produção de dados. As anotações realizadas em campo passam por dois processos, o primeiro é descritivo onde observa-se o local, as pessoas ações e conversas. O segundo é reflexivo, apreende o ponto de vista de quem observa, as impressões e ideias (BOGDAN; BIKLEN, 1994, p. 152).

Para uma maior aproximação dos sujeitos e compreensão do contexto em que estão inseridos, empregou-se o segundo instrumento, as entrevistas semiestruturadas, como principal elemento de produção de dados. Este método de construção articula elementos de entrevistas abertas e estruturadas, onde há perguntas previamente formuladas e o "informante-chave" pode falar livremente sobre o tema proposto, não necessariamente ficando preso ao roteiro construído (MINAYO et al., 2002).

As entrevistas foram realizadas com base em um roteiro composto pelas seguintes questões norteadoras divididas nos seguintes blocos: 1- dados de identificação das entrevistadas e apresentação do propósito da entrevista; 2- investigação sobre os itinerários de vida para se tornar feirante, suas relações com a clientela e local de trabalho; 3- Aspectos relacionados ao comer na feira durante sua rotina de trabalho e seus conceitos de alimentação saudável.

Os acordos de tempo e uso do gravador foram feitos no primeiro contato com as informantes, assim como assinatura do TCLE. Foram realizadas no período de 2 semanas 5 entrevistas individuais, onde cada uma foi denominada pela letra "F", acompanhada de um número (F1, F2, F3, F4 e F5). Cada entrevista teve duração de aproximadamente 30 minutos e após a gravação, as mesmas foram transcritas e avaliadas em uma matriz de análise onde as falas foram categorizadas.

O processo de análise dos dados foi realizado através da análise de discurso. Esta técnica "tem seu ponto de apoio na reflexão que produz sobre o sujeito e o sentido - um relativamente ao outro — já que considera que, ao significar, o sujeito se significa. " (ORLANDI, 2014, p. 55). A partir disto, tem-se o objetivo de interrogar os sentidos estabelecidos em diversas formas de produção, podendo ser verbais e não verbais, onde procura-se compreender os sentidos que o indivíduo manifesta através de seu discurso. 


\section{RESULTADO E DISCUSSÃO}

Os resultados foram organizados em uma matriz de análise culminando nas seguintes categorias: 1) "Primeiro olhar sobre a feira", que apresenta uma visão geral da feira livre de Barreiras/BA; 2) Faces da reforma: "feira hoje parece que tem um dono", que descreve os impactos e as mudanças objetivas e subjetivas que a recente reforma da feira livre provocou à seus feirantes e consumidores; 3) "O se tornar feirante", que dialoga sobre como se dá a construção da profissão e como a feira vai além do trabalho, estabelecendo diversos tipos de trocas, além da mercadoria; 4) "Comida de feira: [...] aqui tem comida de todo tipo", que caracteriza a comida da feira livre e revela as percepções das feirantes sobre a mesma, abordando concomitantemente a acepção do saudável.

\section{1) Primeiro olhar sobre a feira}

$\mathrm{Na}$ contemporaneidade, principalmente nos municípios de pequeno e médio porte, as feiras representavam o polo comercial dessas localidades (FERNANDES et al., 2014). Quanto a ocupação do território, localizavam-se geralmente distantes dos centros das cidades e dos lugares privilegiados, de modo a atender uma demanda popular. Ou seja, situavam-se próximos aos bairros periféricos, onde residiam camadas menos abastada da sociedade (MINNAERT, 2008).

Diferente desta realidade descrita acima, a feira livre de Barreiras/BA está localizada no centro da cidade, como é exibido na Figura 1. Trata-se, de uma localização privilegiada por se comunicar com a avenida principal (a BR-242) onde circulam, além da população, os veículos que transportam viajantes que entram e saem do município; além de ter fácil acesso para moradores de diversos bairros que fazem fronteira com o centro da cidade. Considerada uma importante forma de abastecimento regional, recentemente passou por uma reforma em suas instalações físicas, depois de um incêndio que afetou todo a sua estrutura física e impediu seu funcionamento durante aproximadamente 1 ano naquele local. Após essa reforma, a feira recebeu uma nova forma de organização e o seu funcionamento foi reestabelecido.

Figura 1 - Feira livre de Barreiras - BA

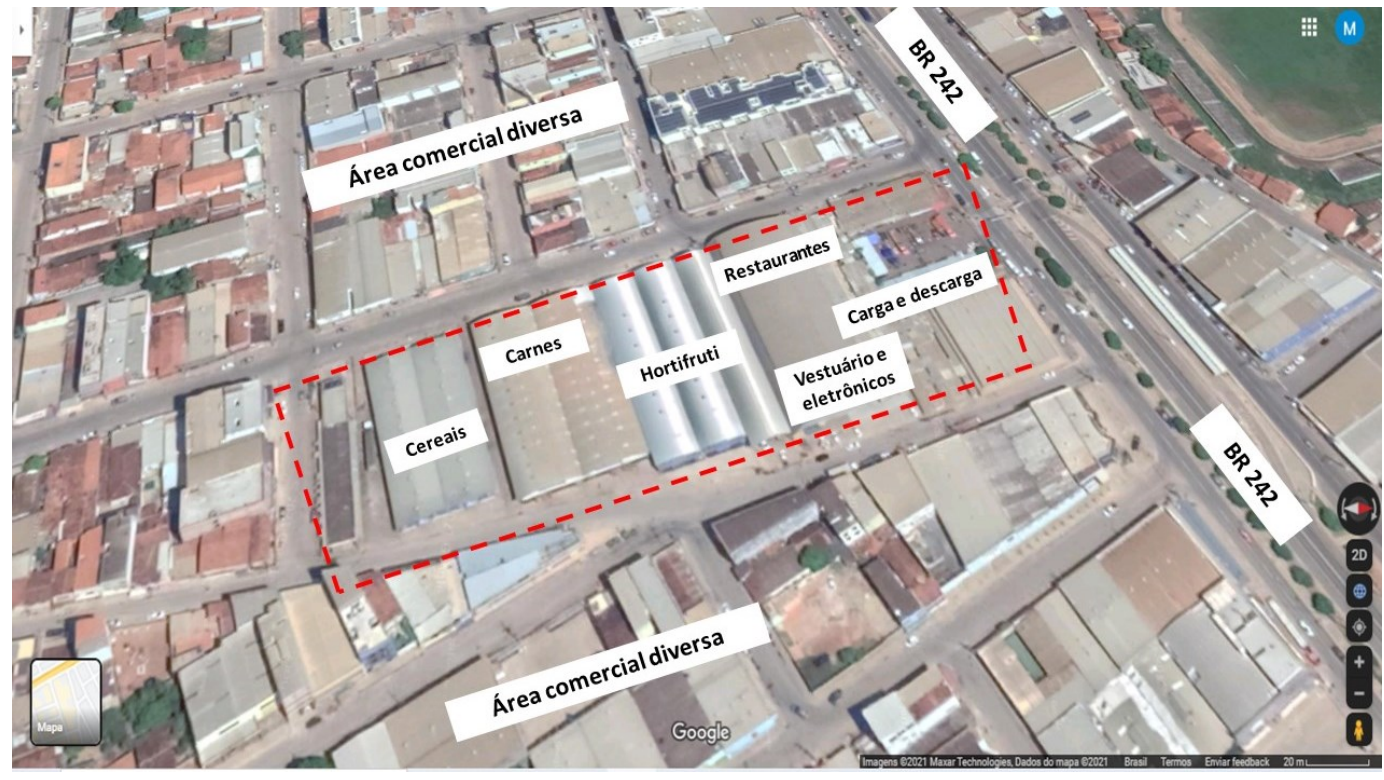

Google Maps com adaptação dos autores

Fonte:

Nota: A linha tracejada vermelha contorna a área da feira livre.

Após esta reestruturação, a feira passou a ser dividida em quatro galpões, o primeiro galpão é destinado aos gêneros de hortifrúti; o segundo à comercialização de carnes, frangos e pescados, condimentos, doces, derivados do leite e produtos panificados; o terceiro à comercialização de grãos e cereais; o quarto e último galpão divide espaço entre o comercio de eletrônicos, vestuário, 
restaurantes e lanchonetes que produzem refeições para os clientes que frequentam o local. Compondo esse cenário também percebe-se a chegada e saída de veículos com as mercadorias a serem comercializadas.

Além dos atos relacionados a comercialização e distribuição de alimentos, esse cenário em movimento que é a feira, está repleto símbolos sociais que de certa forma resistem e se apropriam de um espaço urbano, concebendo uma "experiência peculiar de sociabilidade e de uso da rua" (MASCARENHAS; DOLZANI, 2008).

Para além da delimitação espacial, a caracterização da feira livre não se restringe a demarcações geográficas. Trata-se de um campo delimitado também pelos indivíduos que ali convivem e circulam. Nesse contexto DaMatta (1997) refere que "[...] o espaço é demarcado quando alguém estabelece fronteiras [...] mas nada pode ser tão simples assim, porque é preciso explicar de que modo as separações são feitas e como são legitimadas e aceitas pela comunidade".

Aos sábados, uma rua circunvizinha também é ocupada pelos feirantes. A rua está próxima a um dos galpões e ambos comercializam basicamente os mesmos produtos. Ainda assim, é possível notar diferença na dinâmica desses espaços. No galpão de hortifrúti, nota-se uma movimentação menos intensa, o que resulta em um ambiente mais calmo e ordenado. Percebe-se nesse espaço, a presença de quadros artísticos expostos na parede, que trazem a ideia do aconchego de uma sala de casa. As bancas dos feirantes são dispostas em filas, cada uma em seu espaço demarcado, e ao fundo percebe-se à "cozinha", com pequenos espaços que comercializam comida no local.

Quando se analisa a dinâmica da rua, evidencia-se como esta é um espaço definido precisamente ao inverso da casa. Diferente do galpão de hortifrúti, a rua é bastante movimentada e barulhenta, o espaço é apertado, tanto para clientes, quanto para vendedores que se organizam por conta própria e possuem bancas menos estruturadas e menores. A rua remete a terra que pertence ao "governo" ou ao "povo" e que está sempre repleta de fluidez e movimento, é um local perigoso (DAMATTA, 1997).

Cabe ressaltar que a feira livre por ser um ambiente repleto de códigos sociais próprios, seus conceitos sobre organização podem divergir daquilo que se considera comum e globalizado. Nesse contexto Vedana (2004) caracteriza a feira como um espaço de ordem diferenciada comparada a supermercados, pois na feira raramente se vê filas e embalagens plásticas, mas sim bancas lotadas em um espaço aberto com pessoas que apalpam os alimentos e trocam receitas.

As feiras livres de forma geral comercializam frutas, verduras e legumes, carnes, ovos, leite e derivados, que auxiliam na adoção de padrões alimentares mais saudáveis para a população. A diversidade de produtos é uma marca da feira. Nesse interim, o Guia Alimentar para a População Brasileira (BRASIL, 2014), documento formulado para a Promoção de Alimentação Saudável no Brasil, considera as feiras como importantes instrumentos para a garantia da Segurança Alimentar e Nutricional (SAN), pois se mostram como uma alternativa para compra de alimentos in natura e minimamente processados, com distribuição principalmente por agricultores familiares.

A feira também inclui uma perspectiva além da comercialização de alimentos, pois proporciona uma imersão em um ambiente vivo, onde percebe-se imagens, gestos e ações características. Por refletirem a produção da região onde está situada, em todo o trajeto da feira o paladar, o olfato e a visão são estimulados pelas mais variadas cores, sabores e cheiros, tal contextualização reforça a característica sociocultural das feiras livres.

Com isso, percebe-se que as representações simbólicas extrapolam espaços geográficos, pois tais representações estão também no imaginário das pessoas, determinando assim como o ambiente se estrutura e se reconstrói.

\section{2) Faces da reforma: "a feira hoje parece que tem um dono"}

No período em que a reforma estava em andamento, os feirantes foram remanejados para um local temporário, para que suas atividades não fossem completamente interrompidas e prejudicadas. Após a reforma, os feirantes antigos e novos retornaram a feira central, que apresentava uma nova dinâmica espacial e de funcionamento. Nesse novo cenário, diversas mudanças foram relatadas pelas feirantes: o espaço físico, a assiduidade dos clientes, e a acepção sobre "feira livre ".

A feira não está imune ao "resto" da sociedade, pois não é um resíduo com prazo de validade vencida. A feira, para existir na duração do tempo, tem que ter a capacidade de resistir, ou seja, ser capaz de adaptar-se aos novos padrões sociais e do Estado (SOUZA, 2010, p. 126). Dentre as DOI: http://dx.doi.org/ 10.14393/Hygeia17057222 $\quad$ Hygeia $\quad$ v.17 $\quad$ p. $110-120,2021$ página 114 
alterações, a nova estrutura da feira foi relatada diversas vezes como sendo um ponto positivo, tendo em vista que o lugar tornou-se mais limpo e organizado, assim como relata a F2: pra mim ficou ótimo, que era muita bagunça, era muito desorganizado e ficou mais organizado as bancas, ficou mais espaço nos corredores para as pessoas passar [...] Pra mim só ficou bom por que ficou mais higiênico, mais limpo né.

Cabe-se salientar que os conceitos sobre higiene e organização são múltiplos e depende do lugar de fala de cada sujeito. Na perspectiva da feirante acima, os aspectos higiênicos sanitários foram melhorados com a nova estrutura física e com a nova forma de organização do espaço. Em seu estudo Minnaert e Freitas (2010) abordam diferentes pontos de vista dos feirantes sobre aquilo que é privado e público, limpo e sujo. Tais representações culturais associam aquilo que é compartilhado com outras pessoas como público, podendo assumir automaticamente a condição de sujo. Já aos espaços privados, como a barraca, o corpo e o espaço do feirante, são vistos como limpo.

Em consonância com essa perspectiva, as falas das entrevistadas dialogam com essa tônica vinculada a polissemia dos conceitos de ordem e desordem, a F5 diz: a feira era bagunçada, mas era bagunçada não só por conta do visual da feira, por que o que mudou hoje foi o visual da feira[...] era bagunçada por conta dos drogados, por conta desses loucos que ficam aqui, o bagunçado da feira era isso, não tinha ordem, não tinha policiamento, não tinha guarda e hoje também não tem, então a bagunça da feira continua a mesma.

Percebe-se então que a ideia de bagunça se relaciona não somente com o espaço físico, mas sim com uma bagunça social. Indivíduos que não fazem parte da feira e não deveriam estar ali, na concepção dos feirantes, atrapalham aquela ordem de trabalho e a estrutura do ambiente.

Ao passo que se constata a presença desses indivíduos, o processo de revitalização e reforma da feira provocou uma ambivalência no perfil de clientela dos feirantes. Os mesmos relatam que os clientes antigos se perderam após o processo de mudança e novos clientes foram conquistados, porém com um perfil diferente do que era comum. Para as feirantes, o retorno dos clientes antigos se mostra lento, pois apesar de ser o mesmo espaço, o lugar tornou-se diferente, novo e desconhecido, ou seja, "espaço se torna lugar na medida em que é experienciado e valorizado, que tem significação para pessoa, lugar é mais concreto que espaço" (STANISKI; KUNDLATSCH; PIREHOWSKI, 2014, p. 4). A entrevistada F3 afirma que: gostei não, por que quem tinha seu lugarzinho tinha que ficar no seu lugar[...]pra gente era melhor "mulher", a gente vendia mais, aqui ninguém vende quase nada não".

Percebe-se que o perfil de clientela mudou após a reforma, assim a F5 relata: perfil de clientes que vem mais aqui é variado[...]antigamente vinham mais pessoas com menos condições, mas que compravam mais, hoje em dia vem pessoas que demonstram ter mais condição, mas são pessoas que compram bem menos. Tal constatação se mostra condizente com o processo que Magnani (2002, p. 13) descreve como gentrification, que seria o enobrecimento e requalificação de espaços tidos como antiquados e decadentes. Esse processo intenciona uma nova dinâmica, principalmente nos centros das cidades, onde se estabelece o "consumo do lugar", sendo assim uma nova forma de consumo cultural.

A partir desse contexto, constata-se que reformas de espaços tradicionais podem possuir um viés "higienizador de pessoas", onde a partir do espaço se exclui perfis que não se encaixam mais na nova ordem e estética do lugar. Sendo assim, Jayme e Neves (2010) dizem que: "essas políticas de revitalização se apropriam culturalmente das imagens das cidades, com o objetivo de atribuir novos sentidos ao passado e, muitas vezes, têm um caráter segregador. "

Percebe-se que a moralização desse espaço produziu um novo valor social, favorecendo em alguns casos, a presença de um determinado grupo social e o afastamento de outro. A feirante F5 relata que: como aqui eles acabaram colocando grades na feira né, então o pessoal mesmo que é mais fraco de condição (financeira), eles têm medo até de entrar achando que aqui é mais caro.

Com a nova estrutura, o conceito de feira livre passou a ser ressignificado, pois as feirantes afirmam que as regras estabelecidas retiraram a principal característica da feira, ser livre. A entrevistada F5 discute que: [...] por que antigamente era "feira livre", hoje em dia você não pode chamar mais feira livre, a feira hoje em dia parece que tem um dono. Tal condição se relaciona com a forma com que a feira livre se construiu ao longo da história. 
Os feirantes produziam seus próprios códigos e normas de conduta, estabelecendo assim seu próprio fluxo de trabalho. Diante das novas normas estabelecidas, os feirantes precisam se adequar a algo que não Ihes pertence, que não foi herdado ao seu trabalho, mas imposto ao mesmo.

\section{3) O se tornar feirante}

As feiras livres são consideradas a forma mais antiga de comercialização de alimentos e produtos agrícolas, segundo os registros na literatura, que apontam essa atividade laboral desde 3.000 a.C, onde os povos sumérios realizavam trocas em locais específicos e em dias determinados da semana (SALES; REZENDE; SETTE, 2011). Algumas especificidades dessa modalidade de comércio fazem com que a feira livre possa ser vista por diversos aspectos: econômicos, higiênico-sanitários, socioculturais e até geográficos.

Por ser um espaço que comercializa diferentes tipos de produtos, a feira livre é tida no imaginário das pessoas como um ambiente que vende o "natural", o "fresco", adquirindo também a ideia de um lugar mais barato para se "fazer a feira".

Cavalcanti (2014) afirma que, o natural torna-se o princípio chave para o desbravamento dos significados relacionados a feira, e até mesmo a concepção de alimentação saudável, sendo assim, o natural é que atribui saúde, sabor e frescor. Essa percepção é ilustrada pela fala da F4: eles gostam da feira por que tem vez que é mais barato, mais que o mercado[...] de tudo, todo dia tem um pouco fresco, e no mercado é congelado lá, então aqui é mais em conta e mais fresco, todo dia tem.

Porém, esse lócus não se manifesta apenas como mais uma forma de comércio, pois para as feirantes que ocupam esse espaço, a feira livre vai além do trabalho, torna-se um ambiente de trocas mútuas entre clientes, feirantes e colegas de banca. Essa multiplicidade de sentidos faz parte da construção do ser feirante.

Partindo da cosmovisão das atrizes desse estudo, a feira livre se manifesta não somente como uma forma de sustento através da venda de alimentos in natura, mas também como um local de trocas entre aqueles que ali convivem. Troca-se conhecimento, experiência, amizade, confiança, e se estabelece como um local de pluralidade. Ou seja, a feira se institui como um espaço polissêmico, onde os indivíduos se cruzam, se relacionam e experimentam cotidianamente, as diversidades do ambiente. Os consumidores, turistas, idosos, feirantes e até mesmo crianças dividem o mesmo espaço (ALMEIDA; PENA, 2011).

Nesse contexto, a feira livre de Barreiras torna-se um local onde as relações humanas são experimentadas por todos, em que as feirantes criam uma rede de amizade e confiança que se estende por todo ambiente, assim como relata a entrevistada F2: "aqui é bom por que a gente conhece muita gente, a gente aprende muita coisa né, escuta muitos "causos" das pessoas ai[...] quando eu viajei mesmo o pessoal sentiu falta por que não tava aqui, por que gosta de conversar comigo [...]a gente faz amizade, é muita amizade.

Essa dinâmica que as feirantes têm entre si, faz parte da construção e aprendizagem da própria profissão. O fluxo operacional do trabalho é aprendido com seus companheiros de banca, e muito conhecimento sobre o labor é passado de geração em geração. A proximidade entre os feirantes possibilita o estabelecimento de acordos entre vizinhos de banca. Entre si constroem normas de convivência, em geral válidas apenas para os feirantes que as definem (SATO, 2007). Percebe-se que maioria das feirantes já teve contato com a feira livre em algum momento anterior ao início da sua carreira, tendo em vista que as influências familiares são bastantes presentes desde a infância.

Desta forma, o trabalho se torna uma continuação do serviço familiar, que elas aprenderam com seus pais, desde $o$ ato de plantar o alimento, colher e a comercializá-los na feira, bem como, a forma de negociar com os clientes. No entanto, vale salientar que essa tradição também incorpora os conhecimentos adquiridos no dia a dia.

As feirantes vendem os mesmos produtos que seus pais comercializavam, tornando assim uma herança do habitus. A feirante F5 relata que: meus pais já trabalhavam na feira, já havia ajudado eles desde os oito anos de idade, então achei que era um trabalho bom por que eu poderia trabalhar e poderia ficar com meus filhos.

Em meados dos anos 70 , ocorreu uma intensificação da inserção feminina no mercado de trabalho, com isso uma nova identidade desse gênero passa a ser traçada, revelando um perfil voltado tanto para o trabalho quanto para a família. Mesmo assim, as responsabilidades com afazeres domésticos DOI: http://dx.doi.org/ 10.14393/Hygeia17057222 $\quad$ Hygeia $\quad$ v.17 $\quad$ p. $110-120,2021$ página 116 
e com os filhos permanecem, mostrando a continuidade de um modelo familiar tradicional (BRUSCHINI, 2007).

Ao analisar as características sociais que compõe o grupo de trabalhadores da feira livre, percebe-se uma predominância do gênero feminino na função de feirante. Isso ocorre por que a feira permite o trabalho autônomo e a conciliação com a função de mãe, além de possibilitar a, independência financeira. A entrevistada F4 relata: eu não quero trabalhar pros outros, quero trabalhar pra mim [...] por que você tem sua liberdade, você tem toda liberdade, você vem o dia que quer, no dia que você não quer você não vem.

Nessa realidade, as feiras livres desenharam um novo panorama, onde além das atividades relacionadas a produção dos alimentos em casa, as mulheres adquiriram um protagonismo na composição da renda familiar (ANACLETO; COELHO; CURVELO, 2016). Com a saída de casa da mulher para o mercado de trabalho, este gênero ocupou espaço nas mais variadas profissões de prestígio social, por outro lado, constata-se o predomínio de mulheres em trabalhos precários e informais, geralmente ocupados por aquelas com baixa escolaridade (BRUSCHINI, 2007).

\section{4) Comida de feira: "aqui tem comida de todo tipo"}

Na diferenciação sobre alimentação, se faz necessário uma diferenciação sobre aquilo que é comida e o que é alimento, visto que há compreensões diferentes para esses termos. $O$ alimento seria uma substância ingerida para manter a pessoa viva, já a comida é tudo que se come com prazer, sob as regras de comunhão e comensalidade. O alimento é como uma moldura, já a comida representa o quadro, algo capaz de estabelecer uma identidade individual ou de classes (DAMATTA, 1986).

A partir das informações construídas nas inserções em campo, observa-se que a comida recebe diferentes significados dependendo de qual contexto está inserida, onde a comida do ambiente doméstico é: bem-feita e gostosa (F2), e a comida da feira é descrita como feita de todo jeito, eles fazem pra vender eles querem ganhar dinheiro (F2). Tais representações não se restringem somente a alimentação, mas se direcionam também a objetos e pessoas que passam a ser julgadas a depender do local a que pertençam.

Apesar da feira livre ser um ambiente farto em alimentos in natura e minimamente processados, esses alimentos não fazem parte hábito alimentar dos feirantes e não estão presentes nas refeições que são produzidas pelos estabelecimentos locais. O que passa a ser vendido é representado apenas como uma mercadoria de trabalho, não havendo uma estreita relação com aqueles que comercializam, assim a F3 relata: se fizesse bastante verdura, quem não quisesse comer aquela carne velha ensebada para lá, botava umas verdurinhas e comia verdura, mas eles não fazem nem isso, tanta coisa tem aqui, pepino, tomate, quiabo, maxixe tudo isso é verdura saudável.

A partir dessa percepção, percebe-se que a comida servida na feira se distancia do que Santos (2008) considera como lightização da culinária e do comer, caracterizado como uma modificação nos sistemas culinários pela criação de versões light de preparações ou uma forma ligth de comer pratos tradicionais.

O "saber fazer" (CAVALCANTI; 2014) se torna conceito chave para caracterizar a comida de casa como mais saborosa e saudável, enquanto a comida de feira causa desconfiança. Sobre esses aspectos a F2 relata: eu acho malfeita (risos) eu acho que toda feira a comida é malfeita [...] eu fico com o pé atrás, eu como, mas é de um restaurante mais na frente que eu confio né. Ao analisar esse discurso, percebe-se o estigma que a comida de feira possui, porém quando há a criação de um vínculo com aquele que produz, essa desconfiança torna-se inexistente. Ou seja, o saudável abrange não só aspectos biológicos, pressupõe também as relações de vínculo entre quem cozinha e quem consome.

Nesse contexto, as acepções sobre alimentação saudável se baseiam majoritariamente na forma de preparo, quantidade de temperos e de gordura presente na comida. Tais acepções também variam de acordo com o conhecimento que é adquirido pelos indivíduos, como expressa F1: bom, eu considero uma comida assim, gostosa né, mas, porém, assim muito fraca na nutrição, que nem minha nutricionista recomendou a questão de salada. Observa-se também que os alimentos industrializados e concentrados em aditivos alimentares contrapõem o considerado saudável, a F3: já não é saudável direito por que cê sabe, o gado hoje em dia já anda do jeito que anda né é tudo em cima dos remédios [..]as verduras hoje em dia tudo é com veneno. 
Dessa forma, o saudável é considerado aquilo que não passou pela interferência humana a partir das tecnologias desenvolvidas para melhoramento na produção dos alimentos e produtos comercializados. Neste sentido, o "comer bem" é inerente a qualidade dos produtos, ou seja, considera-se saudável alimentos frescos e naturais, enquanto os produtos congelados e com aditivos/conservantes são vistos negativamente ao "comer bem" (FISCHLER; MASSON, 2010, p. 356).

Cabe considerar que a rotina de trabalho das feirantes também determina sua rotina alimentar, visto que a feira livre está em constante movimentação e as trabalhadoras não dispõem de um tempo reservado para realização das refeições. Sobre essa perspectiva, a entrevistada F1 relata que: eu não considero minha alimentação saudável, as vezes eu opto por uma coisa bem mais rápida né, você come mais depressa pra poder cuidar das coisas, a gente nem pensa muito no que comer, a gente pensa muito no que embalar e botar na banca, em vender e satisfazer o cliente, a gente sempre fica para segundo plano. Ao se pensar nos significados atribuídos a alimentação saudável percebe-se que a mesma se constrói a partir de diferentes pontos de vista alinhados a ciência e a razão.

\section{CONSIDERAÇÕES FINAIS}

O presente trabalho permitiu a compreensão do olhar sobre a feira, para além do seu ambiente e do que ali é comercializado. Tal perspectiva proporcionou maior visibilidade dos atores envolvidos em todo o processo de comercialização e distribuição dos alimentos nesse espaço que também configura-se como o campo de conexão entre as representações simbólicas da casa e a rua. Observa-se também a feira livre como um ambiente vivo e plural que participa da construção do ser feirante, criando assim sua dinâmica peculiar.

A feira livre atualmente passa por um processo de mudança e resistência que ocorrem concomitantemente, pois a nova estrutura adquirida ainda precisa ser vivenciada e experimentada tantos pelos feirantes quanto para os consumidores, para que assim, um novo fluxo seja estabelecido.

Ao se remeter a comida de feira, percebe-se que a acepção do saudável perpassa aspectos nutricionais, reafirmando assim que a alimentação vai além do modelo biomédico de corpo-máquina e se estabelece também como práticas sociais que caracterizam o indivíduo e a população. Sendo assim, se faz importante a construção de pesquisas como esta, que procurem compreender os códigos, os significados e os símbolos sociais que envolvem os indivíduos e são reproduzidos pelos mesmos. Tais estudos que investiguem a parte social da alimentação também são importantes no diálogo de formação em saúde, especialmente nas Ciências da Nutrição. Esses estudos incentivam uma ampliação do olhar para os fenômenos sociais que compõem as práticas alimentares e os sujeitos que fazem parte desse processo.

\section{REFERÊNCIAS}

ALMEIDA, Mirella Dias; PENA, Paulo Gilvane Lopes . Feira livre e risco de contaminação alimentar: estudo de abordagem etnográfica em Santo Amaro, Bahia. Revista Baiana de Saúde Pública, v. 35, p. 110-127, jan./mar. 2011. https://doi.org/10.22278/2318-2660.2011.v35.n1.a1021

ANACLETO, Adilson ; COELHO, Andersandra Pereira ; CURVELO, Eder Bruno Couto . As Mulheres empreendedoras e as feiras livres no litoral do Paraná. Faz Ciência, v. 18, n. 27, p. 118-139, jan/jun 2016.

BOGDAN, Robert C.; BIKLEN, Sari Knopp. Investigação qualitativa em educação: uma introdução à teoria e aos métodos. Tradução Maria João Alvares, Sara Bahia dos Santos. Portugal : Porto Editora, 1994. p. 152. cap. 4. Tradução de: Qualitative Research for Education.

BRASIL. Ministério da Saúde. Secretaria de Atenção à Saúde. Guia alimentar para a população brasileira: - 2. ed., 1. reimpr. - Brasília : Ministério da Saúde, 2014..

BRUSCHINI, Maria Cristina Aranha. Trabalho e gênero no Brasil nos últimos dez anos. Cad. Pesqui. [online], v. $37, \quad$ n. 132 , p. 537-572, set/dez 2007. Disponível em: https://www.scielo.br/scielo.php?pid=S0100-15742007000300003\&script=sci_abstract\&tlng=pt. Acesso em: 1 Jul. 2020. https://doi.org/10.1590/S0100-15742007000300003 
CAVALCANTI, Luiza Guimarães . "Na feira não vende marca. Na feira vende natural": acepções atribuídas à alimentação saudável por trabalhadores de uma feira livre, em Salvador-Bahia. Salvador, f. 69, 2014. Trabalho de Conclusão de Curso (Nutrição) - Universidade Federal da Bahia.

DAMATTA, Roberto . O que faz o brasil, Brasil?. 1. ed. Rio de Janeiro: Editora Rocco, 1986. 128 p.

DAMATTA, Roberto. A casa \& a rua: espaço, cidadania, mulher e morte no Brasil. 5. ed. Rio de Janeiro: Rocco Digital, 1997. p 40 . Disponível em:http://www.tecnologia.ufpr.br/portal/lahurb/wpcontent/uploads/sites/31/2017/09/DAMATTA-Roberto-A-Casa-e-a-Rua.pdf. Acesso em: 14 Fev. 2019.

FERNANDES, Camila et al. A IMPORTÂNCIA CULTURAL DA FEIRA LIVRE DE QUEIMADOS/RJ. In: VII CONGRESSO BRASILEIRO DE GEÓGRAFOS. 2014,p. 3. Anais eletrônicos [...] Vitória/ES, 2014. Disponivel em:http://www.cbg2014.agb.org.br/resources/anais/1/1404679401_ARQUIVO_Arti goFEIRA-ResumoparaoCBG.pdf.>. Acesso em: 1 Jul. 2020.

FISCHLER, Claude ; MASSON, Estelle. Comer: a alimentação de franceses, outros europeus e americanos. São Paulo : Editora Senac São Paulo,, 2010. 356 p.

JACCOUD, Mylène ; MAYER, Robert . A observação direta e a pesquisa qualitativa. In: POUPART, Jean et al. A pesquisa qualitativa : Enfoques epistemológicos e metodológicos. Petrópolis - RJ: Editora Vozes, 2008, p. 215-317. Tradução de: La recherche qualitative .

JAYME, Juliana Gonzaga ; NEVES, Magda de Almeida . Cidade e espaço público: política de revitalização urbana em Belo Horizonte. Caderno CHR,Salvador-BA, v. 23, n. 60, p. 605-617, 2010. Disponível em:https://www.scielo.br/pdf/ccrh/v23n60/v23n60a11.pdf. Acesso em: 1 Jul. 2020. https://doi.org/10.1590/S0103-49792010000300011

MAGNANI, José Guilherme Cantor. De perto e de dentro: notas para uma etnografia urbana . Rev. bras. Ci. Soc., São Paulo, v. 17, n. 49, jun 2002, p. 13. Disponível em: https://www.scielo.br/scielo.php?script=sci_arttext\&pid=S0102-69092002000200002. Acesso em: 1 Jul. 2020. https://doi.org/10.1590/S0102-69092002000200002

MASCARENHAS, Gilmar ; DOLZANI, Miriam C. S. . Feira livre: territorialidade popular e cultura na metrópole contemporânea. Ateliê Geográfico, Goiânia - GO, v. 2, p. 72-87, ago. 2008. https://doi.org/10.5216/ag.v2i2.4710

MINAYO, Maria Cecília de Souza (Org) et al. Pesquisa Social: teoria, método e criatividade. ed. Rio de Janeiro: Editora Vozes, 2002. p. 21 - 22.

MINNAERT, Ana Cláudia de S. Teles . A feira livre sob um olhar etnográfico. In: FREITAS, Maria do Carmo Soares de; FONTES, Gardênia Abreu Vieira; OLIVEIRA, Nilce de (Org.). Escritas e narrativas sobre alimentação e cultura [online]. Salvador: EDUFBA, 2008. cap. 8, p. 130-148. https://doi.org/10.1590/S1413-81232010000700072

MINNAERT, Ana Cláudia de Sá Teles ; FREITAS, Maria do Carmo Soares. Práticas de higiene em uma feira livre da cidade de Salvador (BA). Ciênc. saúde coletiva , Rio de Janeiro, v. 15, Jun 2010.

ORLANDI, Eni Puccinelli . Discurso, imaginário social e conhecimento. Em Aberto, Brasília, n. 61, p. 55, ja/mar 2014.

SALES, Aline Pereira ; REZENDE, Liviane Tourino ; SETTE, Ricardo de Souza . Negócio feira livre: um estudo em um município de Minas Gerais. In: III ENCONTRO DE GESTÃO DE PESSOAS E RELAÇÕES DE TRABALHO. 2011. Anais eletrônicos [...] João Pessoa, 2011. 15 p.

SANTOS, Ligia Amparo da Silva. O corpo, o comer e a comida: um estudo sobre as práticas corporais e alimentares no mundo contemporâneo [online]. Salvador: EDUFBA, 2008. 330 p. Disponível em:https://static.scielo.org/scielobooks/38m/pdf/santos-9788523209087.pdf. Acesso em: 1 Jul. 2020. https://doi.org/10.7476/9788523211707

SATO, Leny. Processos cotidianos de organização do trabalho na feira livre. Psicol. Soc., Porto Alegre, n. 19, 2007. Disponível em:https://www.scielo.br/scielo.php?script=sci_arttext\&pid=S010271822007000400013. Acesso em: 1 Jul. 2020. https://doi.org/10.1590/S0102-71822007000400013

SOUZA, Márcio Nicory Costa. A teia da feira: um estudo sobre a feira-livre de São Joaquim, Salvador, Bahia. Salvador-BA, 2010,p. 126. Tese (Pós Graduação em Ciências Sociais) - Universidade Federal da Bahia. Disponível em:https://repositorio.ufba.br/ri/handle/ri/11114. Acesso em: 14 Fev. 2018.

DOI: http://dx.doi.org/ 10.14393/Hygeia17057222 $\quad$ Hygeia $\quad$ v.17 $\quad$ p. $110-120,2021$ página 119


STANISKI, Adelita ; KUNDLATSCH, Cesar Augusto ; PIREHOWSKI, Dariane . O conceito de lugar e suas diferentes abordagens. Perspectiva Geográfica, Ponta Grossa, v. 9, n. 11, 2014, p. 4.

VEDANA, Viviane . "Fazer a Feira": estudo etnográfico das "artes de fazer" de feirantes e fregueses da Feira Livre da Epatur no contexto da paisagem urbana de Porto Alegre. Porto Alegre, f. 251, 2004. Dissertação (Pós Graduação em Antropologia Social) - Universidade Federal do Rio Grande do Sul. 